\title{
К ВОПРОСУ ОБ ОКИСЛИТЕЛЬНОЙ ДЕСТРУКЦИИ КЕРОГЕНА ДИКТИОНЕМОВОГО СЛАНЦА ЩЕЛОЧНЫМ ПЕРМАНГАНАТОМ КАЛИЯ
}

\author{
А. ФОМИНА, \\ доктор химических наук \\ В. ЕРУСЕНКО
}

\section{I СООБЩЕНИЕ}

Диктионемовый горючий сланец, образование которого геологи в настоящее время относят к нижнему ордовику, является вторым горючим сланцем, залегающим в педрах Эстонской ССР и Ленинградской области.

Хотя содержание органического вещества в нем и не превышает в среднем $20 \%$, но в комплексе с полезными составляющимн минеральной части (сера, калий и др.) он может представить интерес для использования в народном хозяйстве. Тем более, что в ближайшие годы, при открытых разработках фосфоритных залежей на комбинате Маарду, диктионемовый сланец, залегающий в кровле фосфоритных залежей, будет неизбежным отходом разработок. Кроме того, что его выемка будет ложиться расходом на производство фосфоритной муки, при лежании в отвалах он может вызвать неприятные явления. Известно, что диктионемовый сланец способен самовозгораться на воздухе. Вышеуказанные причины обусловливают необходимость изыскания рациональных путей использования попутно добываемого диктионемового сланца уже в ближайшие годы, а с развитием добычи фосфоритов в других районах Прибалтики эта необходимость будет вограстать.

Естественно, что рациональное использование диктионемового сланца возможно только в плане комплёкного применения в народном хозяйстве полезных компонентов минеральной составляющей и органического вещества, а для этого необходимо углуб́ленное изучение его, в том числе и органического вещества - керогена.

Диктионемовый горючий сланец был известен до открытия сланца-кукерсита $\left[{ }^{1}, 2\right]$, но до настоящего времени в нашей стране он не получил практического применения. Хотя в Швеции, не имеющей других горючих ископаемых, его успешно эксплуатируют уже около 20 лет, используя в качестве технологического сырья для термической переработки [3]. В связи с тем, что диктионемовый сланец не получил практического применения, его исследование также не имеет тех объемов и глубины, которые имеют место по сланцу-кукерситу. В особенности весьма общими являются представления о химической природе керогена диктионемового сланца. Работы, которые к настоящему времени уже имеют только историческое значение, довольно подробно комментированы з ряде публикаций и в том числе А. К. Сийрде [4], Л. Наппа, А. С. Фоминой [5] и др. Поэтому в настоящем сообщении целесообразно остановиться только на некоторых последних работах, касающихся изучения диктионемового сланца месторождения Маарду.

Анализ минеральной части и техническая характеристика керогена диктионемового сланца Маардуского месторождения довольно детально представлена в иссле- 
дованиях О. Г. Қиррета с сотрудниками $\left[{ }^{6-8}\right]$ и также А. К. Сийрде [4]. Последняя расширила изучение керогена новыми данными по функциональному анализу кислородсодержащих структурных элементов.

Автором установлено, что кислород керогена диктионемового сланца имеет следующее распределение по функциональным группам: в карбоксильной группе $-2,4 \%$; в карбонильной $-33,1 \%$; в гидроксильной $-9,6 \%$ и наибольшее количество его падает на сложно-эфирные группы - $55,0 \%$. В противоположность керогену кукерсита $\left[{ }^{9}\right]$ органическое вещество диктионемового сланца не обнаруживает так называемого неомыляемого кислорода, более чем в три раза содержит сложно-эфирной формы кислорода и почти в два раза больше карбонильного кислорода, но почти в три раза меньше имеет кислорода в форме свободного гидроксила. Хотя экстрагирование (Сийрде) рядом растворителей и дало несколько более высокие выходы растворимого вещества, чем для кукерсита (этиловый спирт дал максимальный выход $-4,89 \%$ экстракта), тем не менее порядок величин растворимости указывает, что органическая масса диктионемового сланца, также как и кукерсита, относится к керогеновому типу. Однако при термическом разложении керогена диктионемового сланца выход смолы полукоксования значительно ниже, чем для керогена кукерсита, в среднем соответственно 20,0 и $65,0 \%$.

Кероген диктионемового сланца резко отличается от кукерсита и по элементарному составу, что видно из данных, приведенных в табл. 1.

Таблица 1

\section{Элементарный состав керогенов диктионемового и} кукерситного сланцев, \%

\begin{tabular}{|c|c|c|c|c|c|c|}
\hline & \multicolumn{5}{|c|}{ Кероген диктионемового сланца } & \multirow{2}{*}{$\begin{array}{c}\text { Кероген } \\
\text { кукерсита } \\
\text { Раудсепп, } \\
\text { Фомина } \\
\text { и др. } \\
{\left[{ }^{10}\right]}\end{array}$} \\
\hline & $\begin{array}{c}\text { Қиррет } \\
\text { и др. } \\
\text { [6] }\end{array}$ & $\begin{array}{c}\text { Киррет } \\
\text { и др. } \\
{\left[{ }^{7}\right]}\end{array}$ & $\begin{array}{c}\text { Киррет } \\
\text { и др. } \\
{\left[{ }^{8]}\right.}\end{array}$ & $\begin{array}{c}\text { Сийрде } \\
{\left[{ }^{4}\right]}\end{array}$ & $\begin{array}{c}\text { Наппа, } \\
\text { Фомина } \\
{\left[{ }^{5}\right]}\end{array}$ & \\
\hline $\begin{array}{l}\mathrm{C} \\
\mathrm{H} \\
\mathrm{S} \\
\mathrm{Cl} \\
\mathrm{N} \\
\mathrm{O} \text { (по } \\
\text { разности) }\end{array}$ & $\begin{array}{c}64,1 \\
7,6 \\
2,2 \\
-\overline{4,2} \\
25,0 *\end{array}$ & $\begin{array}{c}68,7 \\
8,3 \\
2,6 \\
\overline{3,7} \\
16,7^{*}\end{array}$ & $\begin{array}{c}76,8 \\
7,4 \\
2,5 \\
1,9 \\
12,2^{*}\end{array}$ & $\begin{array}{c}69,9 \\
6,6 \\
1,6 \\
-\overline{2,0} \\
19,9 *\end{array}$ & $\begin{array}{c}68,3 \\
7,5 \\
- \\
-\overline{3,2} \\
21,0^{* *}\end{array}$ & $\begin{array}{r}77,1-77,8 \\
9,5-9,8 \\
1,7-2,0 \\
0,6-1,0 \\
0,3-0,4 \\
10-10,2\end{array}$ \\
\hline
\end{tabular}

* $\mathrm{O}+\mathrm{Cl}$ по разности.

** $\mathrm{O}+\mathrm{S}+\mathrm{Cl}$ по разности.

Хотя диктионемовый сланец древнее кукерсита по происхождению, однако в керогене его содержится в 5-8 раз больше азота.

Исследования показали [5], что часть его способна гидролизоваться минеральными кислотами с образованием аминокислот, главным образом алифатического ряда. Из гидролизата керогена диктионемового сланца были идентифицированы глицин, $\alpha$-аланин, $\gamma$-аминомасляная кислота, валин, лейцин, изо-лейцин, серин, глутаминовая кислота, фенил-аланин и пролин.

Уже по этим данным можно заключить, что часть вещества керогена диктионемового сланца представлена как алифатическими, так и ароматическими структурными элементами, которые в макромолекулярном веществе керогена в значительной мере связаны гетероатомными-кисіородными, азотными и другими связями. Однако азотсодержащие структурные элементы керогена диктионемового сланца могут характеризовать только небольшую часть керогена. 
Поэтому для выяснения химической природы керогена в целом необходима постановка исследований в плане более широкого выделения его структурных элементов. Одним из методов исследования химической природы полимерных материалов, в том числе и твердых горючих ископаемых, является изучение продуктов термического разложения. Несомненно продукты термического разложения в определенной мере характеризуют имеющиеся различия в химической природе твердых горючих ископаемых.

Так, в условиях полукоксования в алюминиевой реторте А. Т. Кылль и А. А. Эленурм [11] из диктионемового сланца месторождения Маарду получили на кероген $19,8 \%$ смолы, $18,3 \%$ воды разложения и $16,5 \%$ газа, т. е. $54,6 \%$ летучих веществ, ьместо $86,0 \%$ на кероген кукерсита.

В условнях термического разложения мелкозернистого сланца с твердым теплоносителем при температуре $505^{\circ}$ выход смолы достигал 20,5\% [12], что, однако, не меняет порядок величнны, соответствующей выходу. смолы полукоксования по данным и других авторов. Обращает на себя внимание, с одной стороны, высокий выход воды разложения при полукоксовании, а с другой - низкое содержание фенолов в смоле. По данным Сийрде [4], содержание в смоле кислых соединений достигает 9,7\%, по результатам исследований Қылля, Лаус и Эленурма [12], выход кислых соединений максимально поднимается до $11,0-11,5 \%$ (при термическом разложении в интервале температур $460-505^{\circ}$ ), т. е. образуются ничтожные количества фенолов по весу на кероген - около 2\%, вместо $15-16 \%$ на кероген кукерсита. Смола полукоксования диктионемового сланца содержит заметные количества азотистых оснований - 4,62\% [4], представленных главным образом пиридиновыми основаниями [13]. Суммарное содержание серы в интервале максимального выхода смолы достигает 2,2-2,8\%, представленной, по-видимому, главным образом тиофановыми соединениями, не удаляющимися при очистке серной кислотой [11].

Для легкой фракции смолы полукоксования кукерсита (до 200) характерно высокое содержание олефинов, достигающее $60-65 \%$, а в соответствующей фракции смолы диктионемового сланца содержание олефиновых углеводородов не достигает и $10 \%$. Основной группой соединений бензина диктионемового сланца являются ароматические углеводороды - 68,3\% [ [4]. По данным спектрального анализа, ароматические углеводороды смолы диктионемового сланца представлены как соединениями бензольного ряда, так и полициклическими ароматическимиे углеводородами $\left[{ }^{13}\right]$. Однако, если даже принять, что $80 \%$ общей смолы диктионемового сланца представлено ароматическими соединениями нейтрального, кислого и основного характера, то и в этом случае в летучие соединения переходит не более $16,0 \%$ керогена в виде ароматических соединений. Главная масса органического материала (более $40 \%$ ) остается в виде нелетучего высокоуглеродистого остатка - в полукоксе.

Таким образом, в результате анализа данных исследований термического разложения керогена диктионемового сланца остается очень много неясного. Подойти ближе к толкованию этих неясностей можно при получении большого количества данных о химической природе исходного керогена путем химической деструкции его, обеспечивающей прямое выделение структурных элементов.

Ранее указывалось, что минеральные кислоты (соляная и серная) позволили деструктировать часть вещества керогена диктионемового сланца до растворимых алифатических и ароматических аминокислот, природа и строение которых устанавливаются как физическими, так и химическими методами. Исследование химической природы керогена кукерсита путем окислительной деструкции щелочным перманганатом калия $\left[{ }^{14}, 15\right]$ позволило установить химическую природу преобладающей части его углерода (до 70\%) в виде растворимых, идентифицируемых соедннений насыщенного ряда. Поэтому вполне логичным являлось применение вышеуказанного метода для изучения химической природы керогена диктионемового сланца. Результаты первого этапа этого исследования излагаются ниже. 


\section{Экспериментальная часть}

В качестве сырья для исследования был использован концентрат диктионемового сланца флотационного обогащения, приготовленный в секторе обогащения Института химии АН ЭССР из сланца месторождения Маарду. Для очистки концентрата от примесей флотационных масел он промывался спирто-бензолом и затем доводился до воздушно сухого состояния.

Технический анализ исходного сланца и концентрата осуществлялся по ГОСТу. Содержание керогена определялось после введения соответствующих поправок на минеральную часть по О. Г. Қиррету и др. [[]. Углерод и водород определяли сжиганием в макропечи. Азот определяли по Қъельдалю, серу общую - поо Эшка, органическую - по разности между содержанием общей серы и неорганической серой (сульфидной + сульфатной). Кислород и хлор определялись по разности. Характеристика нсходного сланца и концентрата иллюстрируется данными табл. 2.

Таблица 2

Результаты технического и элементарного анализа диктионемового сланца и концентрата из него, \%

\begin{tabular}{|c|c|c|c|c|c|c|c|c|}
\hline & \multirow[b]{2}{*}{$\mathrm{W}^{\mathrm{a}}$} & \multirow[b]{2}{*}{$A^{c}$} & \multirow[b]{2}{*}{$\begin{array}{c}\mathrm{CO}_{2} \\
\text { мине- } \\
\text { раль- } \\
\text { ная }\end{array}$} & \multicolumn{5}{|c|}{ Элементарный состав керогена } \\
\hline & & & & C & $\mathrm{H}$ & $\mathrm{N}$ & S & $\begin{array}{l}\text { O } \\
\text { по } \\
\text { раз- } \\
\text { ностн }\end{array}$ \\
\hline $\begin{array}{r}\text { Исходный диктио- } \\
\text { немовый сланец }\end{array}$ & 1,2 & 81,3 & 0,5 & 70,0 & 7,7 & 2,6 & 2,4 & 17.3 \\
\hline $\begin{array}{l}\text { Концентрат дик- } \\
\text { тионемового } \\
\text { сланца (флота- } \\
\text { ционного обога- } \\
\text { щения) }\end{array}$ & 1,3 & 48,6 & 0,5 & 69,9 & 6,9 & 2,1 & 2,2 & 18,9 \\
\hline
\end{tabular}

Окислительная деструкция керогена кукерсита щелочным перманганатом калия показала, что успех исследования зависит прежде всего от правильного выбора условий окисления, главным образом от температуры и длительности взаимодействия керогена с окислителем $\left[{ }^{15},{ }^{16}\right]$. В зависимости от химической природы твердого горючего ископаемого условия окисления меняются, выбор оптимальных условий устанавливается экспериментально.

С целью выбора условий окислительной деструкции керогена диктионемового сланца были поставлены опыты по определению кинетики окисления в пределах температур $50-100^{\circ}$.

Окисление проводилось в круглодонной колбе на глицериновой бане. Постоянство температуры поддерживалось терморегулятором с контактным термометром. Қинетика окисления устанавливалась по расходу перманганата калия, определяемого путем титрования проб исходного щелочного раствора перманганата калия и проб, отбиравшихся из реакционной смеси через определенные промежутки времени. Отбор проб производился через трубку со стеклянным фильтром.

Определение содержания перманганата калия осуществлялось по Либену $\left[{ }^{17}\right]$ обратным титрованием избытка муравьинокислого калия 0,1 н $\mathrm{KMnO}_{4}$.

Для каждого опыта бралась навеска концентрата сланца, эквивалентная 1 г углерода. Концентрат суспензировался в 500 мл 3,5\%-ного раствора перманганата калия в $1 \%$-ном водном растворе едкого калия.

На основании полученных результатов окисления при 50,75 и $100^{\circ}$ построены кривые расхода окислителя во. времени, приведенные на рис. 1. 
Из данных рнс. 1 следует, чго повышениє температуры в пределах $50-100^{\circ}$ резко увеличивает окисление керогена диктионемового сланца. Следовательно, для керогена диктионемового сланца, как и для керогена кукерсита, температура окисления имеет большое значение.

Расход окислителя на 1 г углерода керотена диктионемового сланца и керогена кукерсита $\left.{ }^{16}\right]$ иллюстрируется нижеследующими дағными:

\begin{tabular}{c|c|c} 
На 1 г керогена & При 50 & При $75^{\circ}$ \\
\hline $\begin{array}{c}\text { кукерсита за 6 часов, 2 } \\
\text { диктионемового сланца }\end{array}$ & 4,4 & 6,6 \\
3а 5 часов, 2 & 6,3 & 10,7
\end{tabular}

Из приведенных величин можно было бы заключить, что кероген диктионемового сланца окисляется энергичнее органического вещества кукерсита. Это соответствует и элементарному составу керогенов, так как кероген диктионемового сланца сам по себе содержит больше кислорода, т. е. он является более окисленным в нативном виде.

Однако гравнение кинетики окисления

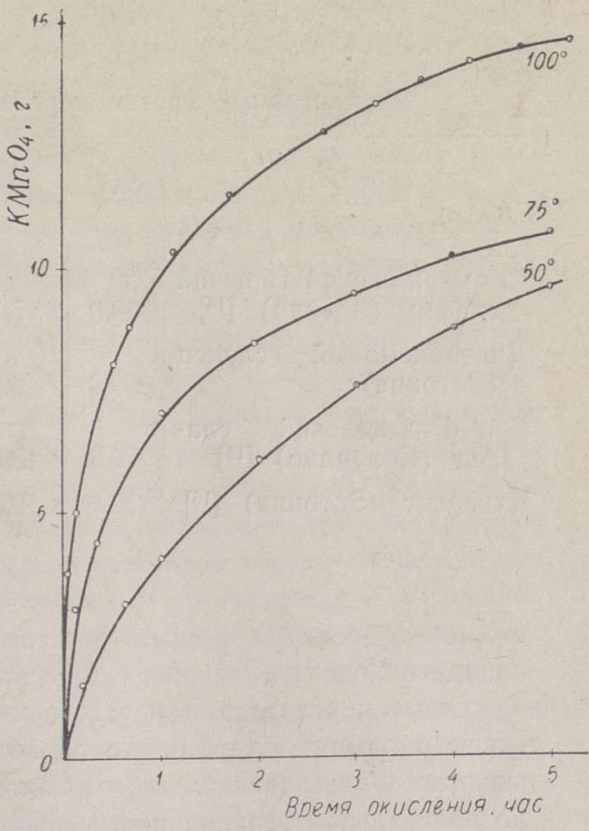

Рис. 1. Кинетика окислительной деструкции керогена диктионемового сланца при разных температурах. щелочным перманганатом калия различных керогенов при $100^{\circ}$ (рис. 2) показывает, что определенной зависимости между скоростью окисления и содержанием кислорода в керогенах не имеется.

Об этом можно судить по кинетике окисления, иллюстрируемой кривыми рис. 2, и

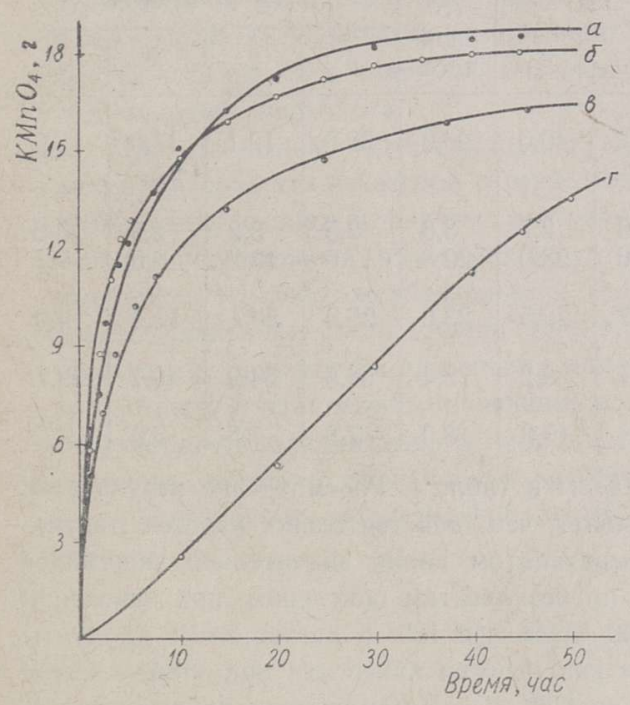

Рис. 2. Кинетика окисления керогенов различных горючих сланцев при $100^{\circ}$.

a - киммериджский горючий сланец (18); $б$ - диктионемовый сланец; в - Грин-Риверовский сланец (Колорадо) (19); 2 - горючий сланецкукерсит (16). элементарным составом керогенов, приведенных в табл. 3.

Судя по элементарным составам, можно заключить, что кинетика окисления приведенных керогенов зависит не только от функциональных групп кислорода, а и от других гетероатомов, а также, очевидни, от химического строения керогенов и минеральной составляющей.

С целью определения количества окисленного углерода и его распределения в продуктах окисления при разных температурах и времени была проведена серия опытов с балансом по углероду. Для окисления бралась навеска концентрата сланца, эквивалентная 10 г углерода. Концентрат суспензировался в 1,6\%-ном водном растворе едкого калия. Окислитель вводился небольшими порциями в сухом виде.

Образующаяся при окислении двуокись углерода определялась из отдельной пробы весовым способом.

Выход летучих с паром кислот устанавливался титрованием дистиллята, полученного при обработке паром подкислен- 
ной пробы, и расчитывался на уксусную кислоту.

Элементарный состав керогенов, \%

\begin{tabular}{|c|c|c|c|c|}
\hline & C & $\mathrm{H}$ & O & $(\mathrm{S}+\mathrm{N})$ \\
\hline $\begin{array}{l}\text { Киммериджский горючий } \\
\text { сланец (Англия) }\left[{ }^{18}\right]\end{array}$ & 69,0 & 7,1 & 13,7 & 10,2 \\
\hline $\begin{array}{l}\text { Диктионемовый сланец } \\
\text { (Эстония) }\end{array}$ & 69,9 & 6,9 & 18,9 & 4,3 \\
\hline $\begin{array}{c}\text { Грин-Риверовский } \\
\text { нег (Кола- } \\
\text { (Колодо) } \\
{\left[{ }^{19}\right]}\end{array}$ & 76,2 & 10,0 & 9,0 & 3,4 \\
\hline Кукерсит (Эстония) [16] & 77,6 & 9,5 & 10,0 & 2,9 \\
\hline
\end{tabular}

Шавелевая кислота определялась осаждением в виде кальциевой соли, с последующим титрованием еe 0,1 н $\mathrm{KMnO}_{4}$ в присутствии серной кислоты.

Остальные, нелетучие с паром растворимые в щелочи продукты окисления, опреде. лялись по весу следующим образом. Подкисленный раствор после отделения щавелевой кислоты и летучих с паром кислот упаривался досуха и высушивался в вакууме до по-

стоянного веса. Затем сухой остаток подвергался исчерпывающему экстрагированию в аппарате Сокслета сначала сухим этиловым эфиром, затем абсолютным ацетоном.

Остаток углерода в нерастворимом остатке определялся после растворения двуокиси марганца в результате обработки щавелевой кислотой в присутствии серной кислоты. Фильтрованием его отделяли от раствора, затем тщательно промывали водой до нейтральной реакции промывных вод и высушивали в вакууме. Углерод в нелетучих с паром продуктах и нерастворимом остатке определялся сжиганием в макропечи.

Таблица 4

Окисление керогена диктионемового сланца щелочными перманганатами калия с балансом по углероду

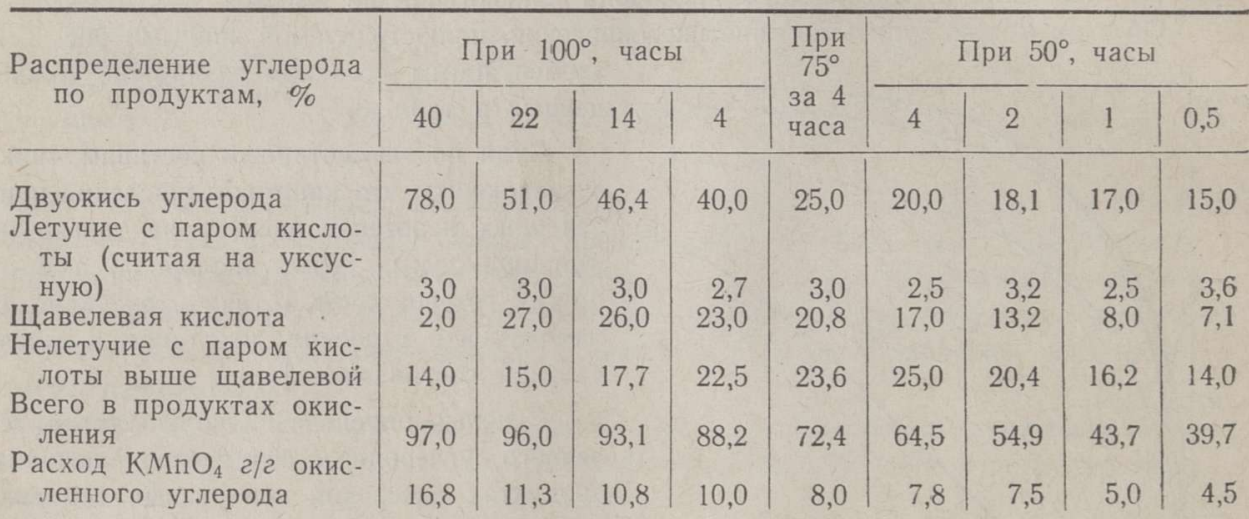

Результаты данной серии опытов приведены в табл. 4. Рассмотрение результатов окисления (с балансом по углероду) показывает, что, действительно, кероген диктионемового сланца окисляется щелочным перманганатом калия значительно энергичнее керогена кукерсита. Об этом можно судить по результатам окисления: при окислении керогена диктионемового сланца в течение 40 часов при $100^{\circ}$ в растворимые продукты переходит свыше 90\% углерода, в то время как кероген кукерсита при этой же температуре за 90 часов окисляется менее чем на $80 \%$ [16]. Рассматривая полученные результаты с точки зрения выбора наиболее выгодных условий, можно сделать ряд выводов. Во-первых, температура $100^{\circ}$ очевидно непригодна для керогена диктионемового сланца в еще большей мере, чем для керогена кукерсита, так как при окислении в интервале от 40 до 4 часов преобладающая часть углерода керогена получается в виде двуокиси углерода и ничего не выясняющей щахелевой кислоты. Несколько лучше результаты 4-часового окисления при $75^{\circ}$. Однако и в этом случае в продуктах 
окисления, пригодных для выяснения химической природы диктионемового сланца, получено менее $30 \%$ углерода. Даже при $50^{\circ}$ окисление керогена диктионемового сланца протекает очень глубоко. Так, на углерод в растворимых продуктах за 0,5 часа при $50^{\circ}$ получается в виде двуокиси $37,8 \%$ углерода, в виде щавелевой кислоты $17,9 \%$. В то время как углерод керогена кукерсита в этих условиях дает только $28,4 \%$ в виде двуокиси углерода и $5,7 \%$ в виде щавелевой кислоты [15] или суммарно в «слепых» продуктах получается соответственно $55,7 \%$ и 34,1\%. Во-вторых, снижение температуры окисления и сокращение времени взаимодействия приводит к тому, что в растворимые продукты переходит только 40-65\% углерода. Следовательно, в плане изучения химической природы диктионемового сланца непригодно как длитєльное непрерывное окисление, так и краткое окисление при $50^{\circ}$ и 0,5 часа. В-третьих. опыты окисления при $50^{\circ}$ с длительностью от 4 до 0,5 часа показалі, что выход продуктов на окисленный углерод нанболее оптимальным получается для окисления в течение одного часа. Поэтому с целью получения большего количества углерода в виде соединений, пригодных для установления природы исходного керогена, следует избрать температуру не выше $50^{\circ}$ с длительностью окисления в течение 1 часа, а для того чтобы получить более высокий процент углерода в растворимых соединениях, обработку керогена следует проводить методом ступенчатого окисления, с удалением из сферы реакции растворимых продуктов деструкции после каждой ступени.

Из полученных результатов и литературных данных также можно сделать предварительное заключение и о химической природе керогена диктионемового сланца, а именно: поскольку при $100^{\circ}$ за 40 часов более $95 \%$ углерода керогена переходит в растворимые соединения, постольку можно считать, что в его структуре почти нет высококонденсированных ароматических структурных элементов, устойчивых к данному окислителю [20]. Кроме того, если учесть, что при полукоксовании диктионемового сланца получается высокий выход воды разложения и полукокса, а при окислении щелочным перманганатом калия высокий выход двуокиси углерода и щавелевой кислоты, то можно предположить, что в структуре этого керогена значительную роль играют термически неустойчивые кислородные производные, образующие в момент термической реконструкции высокореакционноспособные соединения, вступающие между собой в реакции полимеризации и конденсации с образованием нелетучих веществ, которые под влиянием температуры претерпевают дальнейшие превращения с образованием полукокса.

При сравнении литературных данных по окислению щелочным перманганатом калия материалов известной химической природы $[20,21]$ с поведением керогена диктионемового сланца в равных условиях, а также при термическом разложении его, можно предположить, что в его структуре могут играть значительную роль структурные элементы либо оксибензольного типа, либо углеводного характера. Известно, что кероген диктионемового сланца термически устойчивее керогена кукерсита $\left[{ }^{4}\right]$ и его разложение начинается при более высокой температуре. Поэтому имеется основание предполагать, что легко окисляющимися до двуокиси углерода и щавелевой кислоты структурными элементами, а при термическом разложении образующими нелетучий пелукокс, являются производные оксибензольного ряда.

Исследованне окислительной деструкции керогена диктионемового сланца продолжается

\section{Л И Т Е Р А Т Р А}

1. E. Eichw a ld, Fossile Reste in Obergangskalk von Estland und Odinsholm, Leonhards u. Brohns Neues Jahrbuch, 93, 1840.

2. Fr. Sehmidt, Untersuchungen über die silurische Formation von Estland, Nord Livland u. Kurland, Archiv für Naturkunde, Ser. I, B. II, Dorpat, 1858.

3. K. B remmer, Die Entgasung von Öilschiefer unter Tage bei Kvarntrop in Mittelschweden. Glückauf, 91, H-27/28, 1953.

4. А. К. С и й р д е, Некоторые новые данные о диктионемовом сланце. Тр. Таллин ского политехнического ин-та, сер. А, № 73, 1958. 
5. Л. Н апп а, А. С. Фомин а, К вопросу об азоте органического вещества диктионемового сланца. Изв. АН ЭССР. Сер. физ.-матем. и техн. наук, 9, 3, 1960.

6. O. Kirret, N. Gerassimov, A. T ikk, Diktüoneema kiltkivi termilisest lagundamisest. Tead--tehn. kogumik, 10, Tallinn, 1948.

7. О. Г. Киррет, Н. К. Полика рлов, И. Л. Луцковская, Р. С. В алдек и Ю. И. Э й 3 е н, О составе и свойствах диктионемового сланца месторождения Маарду ЭССР. Изв. АН ЭССР. Сер. техн. и физ.-матем. наук, 6, 2, 1957.

8. O. Kirret, E. Koch, L. Rü nd a l, Maardu leiukoha diktüoneemakilda ja temas sisalduva kerogeeni keemilisest koostisest. ENSV TA Toimetised. Tehn. ja füüs.mat. tead. seeria, 8, 4, 1959.

9. А. Я. А а р н а, Э. Т. Л и п п м а, О структуре керогена прибалтийского горючего сланща. Тр. Таллинского политехнического ин-та. Сер. А, № 63, 1955.

10. Х. Т. Р а уд с еп п, А. С. Фомина, Б. К. Торп ан, Х. К. Норман, Техно-химическая характеристика кукерского сланца западного крыла эстонского сланцевого бассейна. Тр. Таллинского политехнического ин-та. Сер. А, № 57, 1954.

11. А. Т. Қылль, А. А. Элену рм, Термическая переработка диктионемового сланца. Ж. Газовая промышленность, № 6, 1959.

12. А. Т. К ыл ль, Т. Н. Л а у с, А. А. Э ле н ур м, Термическая переработка диктионемового сланща с применением твердого теплоносителя. Тр. Ин-та химии АН ЭССР, вып. 3, 69-76, 1959.

13. О. Г. Эй з ен, С. В. Ки в иряхк, А. П. Когерман; Т. Н. Л аус, И. Х. Арро, О химическом составе смолы диктионемового сланца. Химия и технология топлива и масел, № 9, 37-42, 1960.

14. А. С. Фомин а, Л. Я. Побуль, Окислительная деструкция керогена кукерсита (сообщение четвертое). Нзв. АН ЭССР, 4, 4, 1955.

15. Л. Я. Побуль, А. С. Фомин а, Новый источник сырья для получения двухосновных кислот. Изв. АН ЭССР. Сер. техн. и физ.-матем. наук, 4, 2, 1957.

16. А. С. Фоми н а, Л. Я. Побу ль, Окислительная деструкция керогена кукерсита (сообщение первое). Изв. АН ЭССР, 2, 1, 1953.

17. F. P. Tr ed we l1, Kurzes Lehrbuch der analytischen Chemie, Bd. II, Leipzig, 1921.

18. A. L. D ow n and G. W. Hi mus, A Preliminary Study of the Chemical Constitution of Kerogen. Inst. Petrol., 27, 1941.

19. W. S. Robinson, K. H. He a d y, and A. B. Hubbard, Alkaline Permanganate Oxidation of Oil-Shale Kerogen. Ind. Eng. Chemistry, 45, 4, 1953.

20. R. B. R a nd a 11, M. B enger and C. M. G r o o c o ck, Researches on the Chemistry of Coal. Proc. Roy. Soc. A. 165, 992, 1938.

21. W. A. B on e, L. G. Porsons, R. H. Sapiro and C. M. Groocock, Researches on the Chemistry of Coal, VIII, Proc. Roy. Soc. A. 148, 865, 1935.

\title{
Ннститут химии \\ Академии наук Эстонской ССР \\ 30. I 1963 \\ DIKTÜONEEMAKILDA OKSÜDEERIVAST DESTRUKTSIOONIST LEELISELISES KAALIUMPERMANGANAADI LAHUSES
}

Поступила в редакцию

\author{
A. Fomina, \\ keemiateaduste doktor
}

V. Jerussenko

Resümee

Artiklis esitatakse uurimistöö esimesel etapil saadud andmed diktüneemakilda kerogeeni oksüdeeriva destruktsiooni kohta kaaliumpermanganaadi leeliselises keskkonnas. Määrati oksüdatsiooni kineetika $100^{\circ}, 75^{\circ}$ ja $50^{\circ} \mathrm{C}$ temperatuuril. Selgus, et temperatuuri tõus avaldab diktüoneemakilda kerogeeni óksüdeerimisele veelgi ebasoovitavamat mõju kui kukersiidi puhul.

Täiesti kõlbmatuks oksüdeerimistemperatuuriks osutus $100^{\circ} \mathrm{C}$, sest 4 -40 tunni jooksul läks $72-80 \%$ hapendunud süsinikust lahustuvatesse saadustesse ballastainetena nagu $\mathrm{CO}_{2}$ ja oblikhape, millede järgi ei saa määrata lähteainete olemust.

Parimaid tulemusi andis $1 / 2-1$-tunniline oksüdeerimine $50^{\circ} \mathrm{C}$ temperatuuril. Neis tingimustes õnnestus vähendada ballastainete hulka $25 \%$-le ja alla sellegi. 1 tunni jooksul ei lähe lahustuvatesse ühenditesse rohkem kui $44 \%$ lähtekerogeeni süsinikust. Sellest järel- 
dub, et diktüoneemakilda keemilise loomuse tundmaöppimiseks tuleb, nagu kukersiidigi puhul, kasutada astmelist oksüdeerimist. Süsinikubilansist (tab. 5) lähtuvate oksüdeerimiskatsete ja diktüoneemakilda reageerimise põhjal termilise lagunemise käigus oletatakse, et kerogeeni koostises on oluline osa oksüaromaatse struktuuriga elementidel.

\title{
Eesti NSV Teaduste Akadeemia Keenia Instituut \\ Saabus toimetusse 30. I 1963 \\ ON THE PROBLEM OF THE OXIDIZING DESTRUCTION OF DICTYONEMA SHALE KEROGEN WITH ALKALINE POTASSIUM PERMANGANATE
}

\author{
A. Fomina, V. Yerusenko
}

\section{Summary}

The authors present the results of the first series of researches on the oxidizing destruction of dictyonema shale kerogen with alkaline potassium permanganate. The kinetics of oxidation have been defined at 100,75 , and $50^{\circ} \mathrm{C}$. It has been stated that for dictyonema shale kerogen a heightening of the oxidation temperature is even less suitable than for kukersite.

The temperature of $100^{\circ} \mathrm{C}$ proved to be altogether unsuitable, since at an oxidation of 4 to 40 hours duration, $72-80 \%$ of the oxidized carbon turned into dissoluble products in the shape of ballast compounds of carbon dioxide and oxalic acid, on the basis of which it is impossible to determine the nature of the initial substances.

The most suitable temperature proved to be that of $50^{\circ} \mathrm{C}$, with an oxidation duration of not more than $0.5-1$ hour. In such conditions it is possible to reduce the yield of ballast compounds to $15 \%$ and even less. However, in the course of one hour no more than $44 \%$ of the inition carbon of the kerogen turn into dissoluble products. Therefore it has been concluded that for a study of the chemical nature of both dictyonema shale and kukersite it is best to use the method of a stepwise oxidation. On the basis of oxidation experiments with a balance on carbon (5) and the behaviour of dictyonema shale at thermal decomposition it has been conjectured that oxyaromatic structural elements play an important role in the composition of kerogen.

Academy of Sciences of the Estonian S.S.R.,

Received Institute of Chemistry 